\title{
ORORASIOHO
}

Available online at Website http://ejournal.undip.ac.id/index.php/rotasi

\section{ANALISA FORWARD KINEMATIC PADA SIMULATOR ARM ROBOT 5 DOF YANG MENGINTEGRASIKAN MIKROKONTROLER ARDUINO-UNO DAN LABVIEW}

\author{
Munadi \\ Laboratorium Komputasi, Jurusan Teknik Mesin, Fakultas Teknik, Universitas Diponegoro \\ Jl. Prof. Soedarto SH, Tembalang, Semarang 50272 Indonesia \\ E-mail: munadi@undip.ac.id
}

\begin{abstract}
An arm robot simulator has been developed, that capable in simulating a 5 degree of freedom robot manipulator, in which it was equipped with two-finger gripper mechanism at end-effector. This simulator is designed for educational purposes so that many students can easily understand when learning about robot manipulator. The simulator was developed using Ardiuno Uno with LabVIEW through the Firmata interface for controlling the actuators (servo motors). Ardiuno Uno was chosen because it can interact with LabVIEW that will be able to control the angular position of servo motor easily. Angular position errors that occur on the servo motor can be solved by using a numerical program functions and numerical multiply divided on LabVIEW. For analysis, this paper presents the forward kinematics problem which is concerned with the relationship between the individual joints of the arm robot simulator and the position and orientation of the tool or end-effector. The analysis result is carried out in MATLAB.
\end{abstract}

Keywords: arm robot, robot manipulator, Arduino, LabView, forward kinematic

\section{PENDAHULUAN}

Perkembangan teknologi yang meningkat dari tahun ke tahun telah menuntut manusia untuk terus menciptakan alat-alat yang dapat membantu menyelesaikan pekerjaan demi perbaikan kualitas maupun kuantitas dari produk yang dihasilkan. Salah satu contoh alat tersebut adalah robot, dimana alat ini sering diaplikasikan pada bidang otomasi yang dirancang untuk membantu mengerjakan proses kerja yang umumnya memiliki ketelitian yang baik jika dibandingkan dengan manusia menyangkut konsistensi.

Ada banyak definisi yang dikemukakan oleh para ahli mengenai robot. Orang awam beranggapan bahwa robot mengandung pengertian suatu alat yang menyerupai manusia, dimana struktur tubuhnya terbuat dari logam (Novia, Leli, 2004). Dari berbagai definisi, robot dapat dinyatakan sebagai sebuah sistem mekanik yang dikendalikan oleh seperangkat sistem komputer menurut sequence program yang ditanam pada komputer tersebut untuk melakukan berbagai tugas sesuai dengan perintah baik secara semi ataupun otomatis penuh.

Pada awalnya aplikasi robot hampir tidak dapat dipisahkan dengan industri sehingga muncul istilah industrial robot. Definisi yang populer ketika itu, robot industri adalah suatu robot tangan (arm robot) yang diciptakan untuk berbagai keperluan dalam meningkatkan produksi, memiliki bentuk lengan-lengan kaku yang terhubung secara seri dan memiliki sendi yang dapat bergerak berputar (rotasi) atau memanjang/memendek (translasi atau prismatik). Satu sisi lengan yang disebut sebagai pangkal ditanam pada bidang atau meja yang statis (tidak bergerak), sedangkan sisi yang lain yang disebut sebagai ujung (end effector) dapat ditambah dengan tool tertentu sesuai dengan tugas robot, misalnya gripper.

Dengan pesatnya perkembangan robot khususnya di Indonesia saat ini, maka banyak siswa SD sampai dengan mahasiswa tertarik belajar tentang robot. Mereka belajar dari yang sederhana misalnya line-follower sampai dengan yang komplek seperti misalnya humanoid robot. Sementara itu, untuk mempelajari robot dasar yang dipakai untuk industri tentunya butuh peralatan (tools) penunjang yang harganya tidak murah. Oleh sebab itu, maka penelitian ini akan membahas pembuatan simulator arm robot yang merupakan prototipe robot manipulator yang dibutuhkan di dunia industri dengan biaya yang terjangkau untuk kepentingan dunia pendidikan. Pembuatan simulator arm robot dirancang memiliki 5 degree of freedom (dof) dengan menggunakan bantuan software LabVIEW dan mikrokontroler Arduino Uno sehingga memudahkan komunikasi antara perangkat keras arm robot dengan perangkat lunak yang digunakan untuk mengontrol gerakan robot. Selanjtnya dilakukan analisa forward kinemtic untuk mendeskripsikan orientasi dan posisi end effector terhadap base.

\section{ROBOT MANIPULATOR}

Industrial robots adalah robot-robot yang digunakan di dalam industri. Robot-robot industri ini dapat digunakan untuk proses otomasi dalam produksi karena memiliki keakuratan yang tinggi dalam menjalankan tugasnya, misalkan untuk proses welding pada industri otomotif yang ditunjukkan pada Gambar 1. Contoh robot industri yang popular digunakan adalah robot manipulator yang ditunjukkan pada Gambar 2. Robot manipulator memiliki sebuah end effector seperti tangan manusia, diantaranya adalah gripper yang berfungsi untuk memegang atau memindahkan barang. 
Robot manipulator tersebut merupakan sebuah rangkaian benda kaku (rigid bodies) terbuka yang terdiri atas sendi (joint)dan terhubung dengan link dimana setiap posisi joint ditentukan dengan variabel tunggal sehingga jumlah joint sama dengan nilai derajat kebebasan [1].

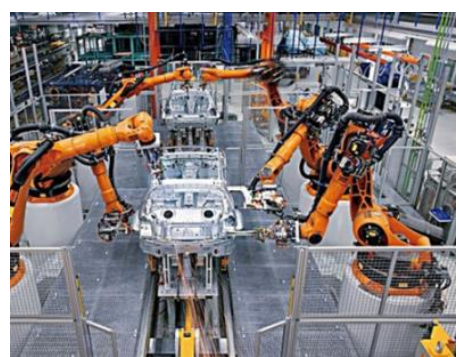

Gambar 1. Robot industri

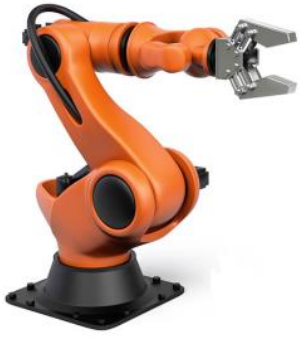

Gambar 2. Robot manipulator

\section{SIMULATOR ARM ROBOT}

Menjadi pertimbangan bagi peneliti untuk membuat alat bantu yang dapat memudahkan pelajar dan mahasiswa dalam mempelajari robot dengan mudah dan murah. Oleh sebab itu, diciptakan simulator arm robot 5 dof sebagai prototipe dari robot manipulator yang sering digunakan oleh industri manufaktur. Gambar 3 menunjukkan desain simulator arm robot 5 dof yang akan dibuat.

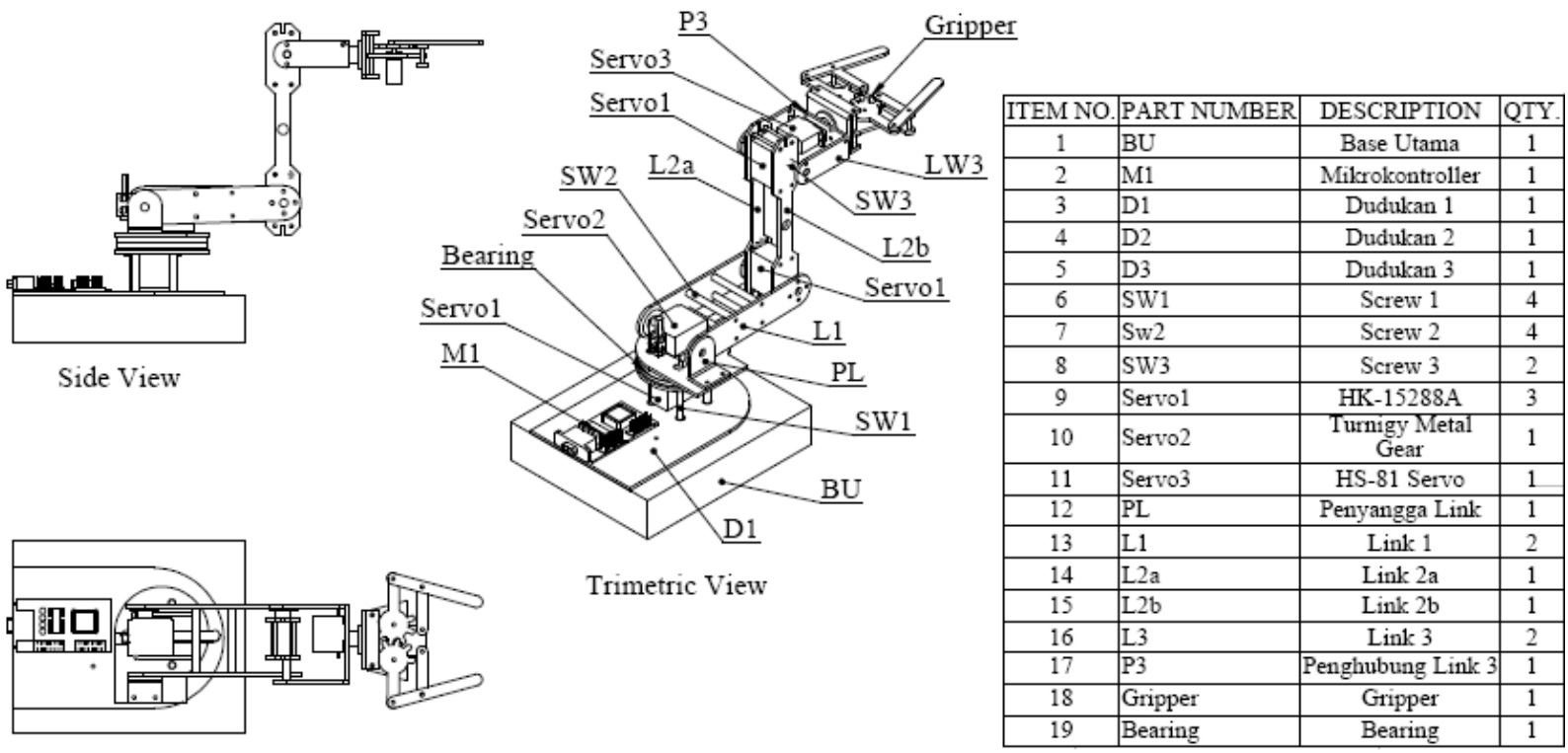

Upper View

Gambar 3. Desain simulator arm robot 5 dof.

\subsection{Perangkat Keras}

Simulator arm robot tersusun atas perangkat keras (hardware) dan perangkat lunak (software). Gambar 4 menunjukkan komponen perangkat keras dan lunak untuk simulator arm robot.

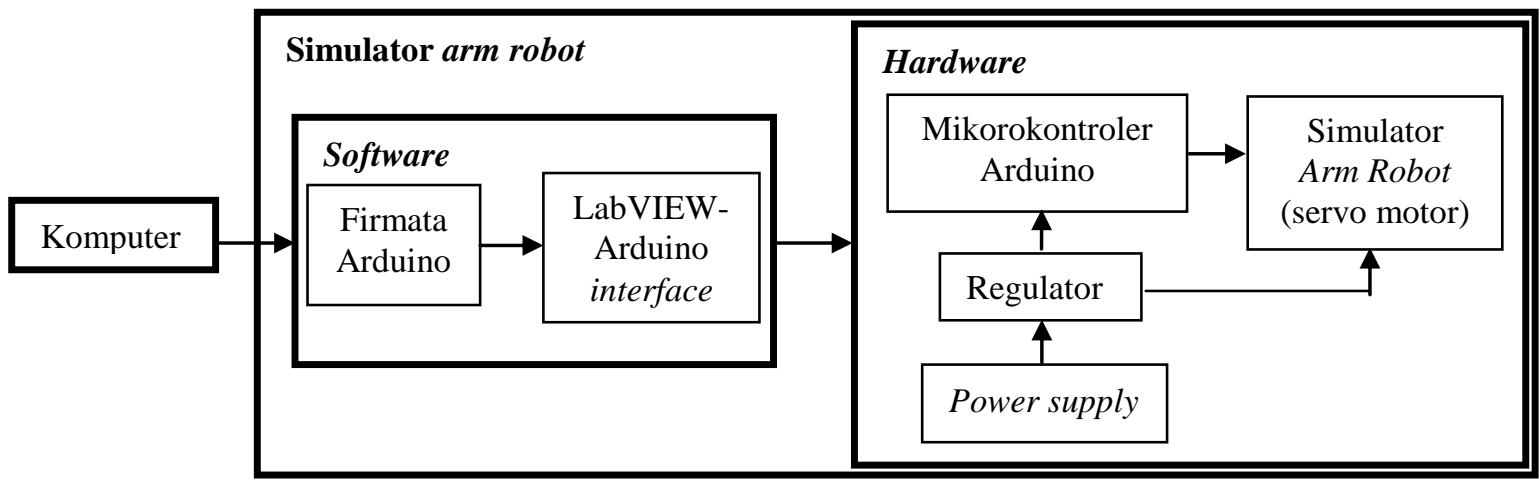

Gambar 4. Diagram hardware dan software arm robot 5 dof 
Selanjutnya, untuk perangkat keras utama yang dibutuhkan terdiri atas:

\section{a. Mikrokontroller}

Sebuah robot membutuhkan kontroler (controller) yang berfungsi untuk mengontrol pergerakan robot yang menyimpan informasi berkaitan dengan data-data robot, seperti data sequence program gerakan robot dengan menggunakan bahasa pemprograman tertentu yang telah diinputkan, misalnya bahasa $\mathrm{C}$ atau $\mathrm{C}++$. Pada penelitian ini, simulator arm robot menggunakan mikrokontroler Arduino Uno yang didalamnya terdapat ATmega328, dan ditunjukkan pada Gambar 5. Mikrokontroler ini mempunyai pin yang cukup banyak pin, memori penyimpanan yang besar serta harganya yang terjangkau. Mikrokontroler ini menggunakan data serial yang dapat dihubungkan dengan USB (Universal Serial Bus) sehingga sangat memudahkan untuk meng-compile program dari labtop/PC ke mikrokontroler. Adapun spesifikasi mikrokontroller ini ditunjukkan pada Tabel 1.

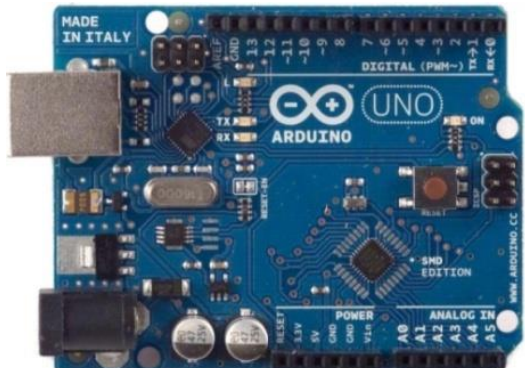

Gambar 5. Arduino Uno.

Tabel 1. Spesifikasi Arduino.

\begin{tabular}{|c|l|l|}
\hline No & \multicolumn{1}{|c|}{ Hal } & \multicolumn{1}{c|}{ Spesifikasi } \\
\hline 1 & Mikrokontroller & ATmega328 \\
\hline 2 & Tegangan operasi & 5 Volt \\
\hline 3 & Tegangan masukan & $7-12$ Volt \\
\hline 4 & Batasan tegangan masukan & $6-20$ Volt \\
\hline 5 & Digital I/O pins & $14(6$ keluaran PWM $)$ \\
\hline 6 & Analog input pins & 6 \\
\hline 7 & Arus per I/O pin & $40 \mathrm{~mA}$ \\
\hline 8 & Arus untuk 3,3 volt pin & $50 \mathrm{~mA}$ \\
\hline 9 & Flash memory & $32 \mathrm{kB}$ \\
\hline 10 & SRAM & $2 \mathrm{kB}$ \\
\hline 11 & EEPROM & $1 \mathrm{kB}$ \\
\hline 12 & Clock speed & $16 \mathrm{Mhz}$ \\
\hline
\end{tabular}

\section{b. Aktuator}

Aktuator yang dipilih adalah servo motor yang merupakan salah satu jenis motor dengan sistem closed feedback. Servo motor yang ditunjukkan pada Gambar 6 terdiri atas dari sebuah motor, serangkaian gear, potensiometer dan rangkaian kontrol. Potensiometer berfungsi untuk menentukan batas sudut dari putaran, sedangkan sudut dari sumbu servo motor diatur berdasarkan lebar pulsa yang dikirim melalui kaki sinyal dari kabel motor. Pada pembuatan simulator arm robot, servo motor yang digunakan untuk joint 1, 3 dan 4 adalah servomotor Hobbyking HK-15288A, untuk joint 2 adalah Turnigy metal gear, dan untuk joint 5 sekaligus pada gripper digunakan servo motor dari Hitec HS-81.
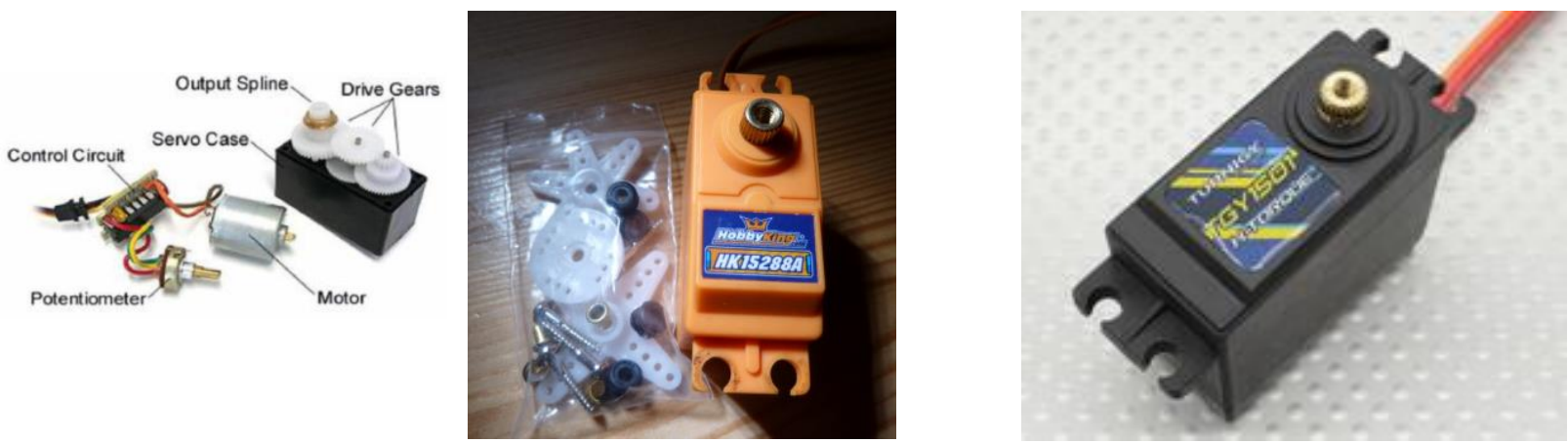

Gambar 6. Servo motor.

\section{c. Regulator}

Agar robot dapat bekerja dengan baik, maka komponen yang tidak kalah penting adalah sebuah regulator yang berfungsi sebagai rangkaian regulasi atau pengatur tegangan keluaran dari sebuah catu daya (power supply) agar efek naik atau turunnya tegangan tidak mempengaruhi tegangan yang masuk ke aktuator atau dapat dikatakan agar tegangan input stabil. Catu daya yang dipilih adalah baterai dengan merk Turnigy yang memiliki kapasitas 1300 mAh, tegangan 11,1 volt. Gambar 7 menunjukkan baterai dan rangkaian regulator yang digunakan. Di sisi lain, simulator arm robot didesain menggunakan servo motor HK-15288A yang membutuhkan tegangan input 6 volt dan servo motor HS-81 yang membutuhkan tegangan input 5 volt. Oleh sebab itu, pada rangkaian regulator ditambah IC-7806 dan IC-7805 untuk menurunkan tegangan sehingga sesuai dengan input servo motor [2]. 

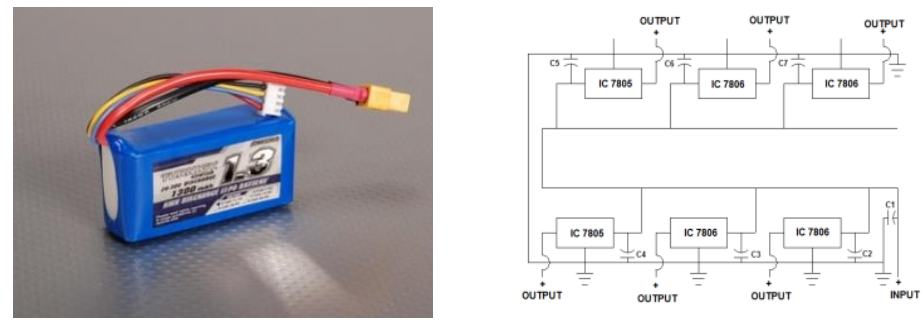

Gambar 7. Baterai dan rangkaian regulator.

\subsection{Perangkat Lunak}

\section{a. MATLAB}

Merupakan bahasa pemprograman tingkat tinggi yang berbasiskan pada matriks. MATLAB secara umum digunakan untuk matematika dan komputasi, pengembangan visualisasi, pemodelan, simulasi dan pembuatan prototype, analisa data, eksplorasi, dan visualisasi, pembuatan aplikasi, termasuk pembuatan antarmuka grafis. MATLAB adalah sistem sistem interaktif dengan elemen dasar basis data array yang dimensinya tidak perlu dinyatakan secara khusus sehingga memungkinkan untuk mememcahkan banyak masalah perhitungan teknik, khususnya yang melibatkan matriks dan vector dengan waktu yang lebih singkat dari waktu yang dibutuhkan untuk menulis program $\mathrm{C}$.

\section{b. LabVIEW}

LabVIEW adalah produk dari National Instruments yang berupa software pengembangan program aplikasi dan hardware input-output untuk keperluan akusisi dan pengendalian. Sedangkan perangkat lunak atau software LabVIEW merupakan sebuah bahasa pemograman graphical yang menggunakan simbol (ikon) untuk membuat aplikasi. Sementara itu, Visual Instruments (VIs) adalah program LabVIEW yang menirukan instrumen sebenarnya dalam bentuk simbol-simbol. Selanjutnya untuk membuat tampilan program aplikasi LabVIEW, digunakan tools dan objek. Tampilan aplikasi ini kemudian dikenal dengan jendela front panel yang berisikan kode representasi dari simbol sebagai fungsi untuk mengatur objek. Adapun source code simbol tersebut ada dalam tampilan jendela block diagram. Jadi pada dasarnya software LabVIEW terdiri dari 3 (tiga) komponen utama, yaitu front panel, block diagram dan tipe data [3]. Front panel merupakan penghubung (interface) antara pengguna (user) dengan program aplikasi. Block diagram merupakan jendela tempat menuliskan perintah dan fungsi, berisikan source code berupa simbol-simbol, node dan garis sebagai data flow untuk mengeksekusi program termasuk kode dari front panel. Gambar 8 (a) menunjukkan tampilan jendela front panel dan (b) menunjukkan tampilan jendela block diagram LabVIEW. Sedangkan dalam membuat aplikasi VIs, harus diperhatikan tipe data tiap simbol agar data flow dapat berjalan semestinya. Tipe data yang tersedia yaitu numerik, boolean dan string. Tipe data dari sebuah simbol dapat diketahui dari warna node atau warna kabel ketika dihubungkan ke simbol lainnya

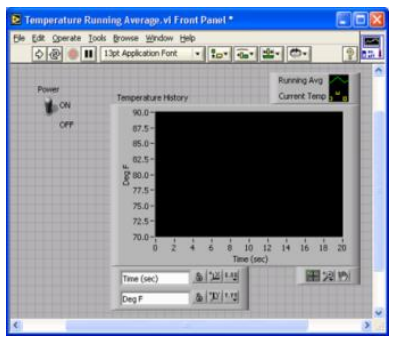

(a)

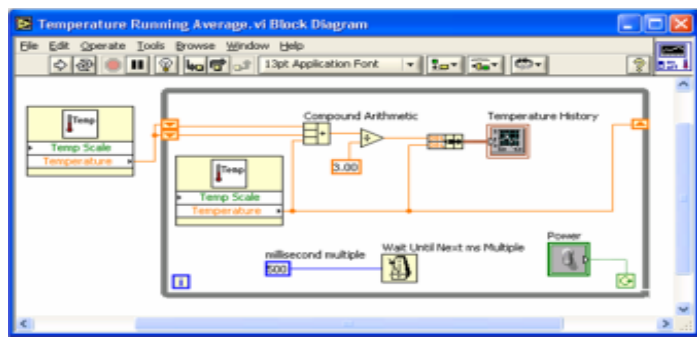

(b)

Gambar 8. Front panel (a) dan block diagram (b) pada LabVIEW

\section{c. Arduino Software (Firmata-Arduino)}

Arduino diciptakan untuk para pemula bahkan yang tidak memiliki dasar bahasa pemograman sama sekali karena menggunakan bahasa $\mathrm{C}++$ yang telah dipermudah melalui library. Arduino menggunakan software processing yang digunakan untuk menulis program kedalam Arduino. Processing sendiri merupakan penggabungan antara bahasa $\mathrm{C}++$ dan Java. Software IDE Arduino terdiri dari 3 bagian yaitu editor program, compiler, dan Uploader [4]. Pada penelitian ini menggabungkan Arduino yang harganya murah dan LabVIEW yang memiliki aplikasi front panel yang tak terbatas dalam berbagai bidang aplikasi, maka perlu adanya komunikasi yang dapat menjembatani antara Arduino dengan LabVIEW, yaitu komunikasi serial Firmata yang merupakan sebuah protokol yang ditulis pada mikrokontroler (salah satunya adalah mikrokontroler Arduino). Firmata ini ditulis untuk memudahkan komunikasi Arduino dengan perangkat lunak yang lain termasuk LabView. 
Firmata ini dapat memudahkan kita dalam membuat program karena tidak lagi dilakukan di kedua sisi, tetapi hanya di satu sisi yaitu sisi perangkat lunak komputer saja (LabVIEW).

\section{HASIL DAN PEMBAHASAN}

\subsection{Forward Kinematik}

Untuk dapat menentukan orientasi dan posisi link robot, maka dibutuhkan pemodelan kinematik. Dalam robotika, pemodelan kinematik merupakan bentuk pernyataan berisi deskripsi matematik geometri dari suatu struktur robot yang bergerak tanpa mempertimbangkan gaya penyebabnya. Dengan analisa forward kinematic, maka dapat ditentukan referensi input tiap aktuator yang berupa besaran sudut agar robot dapat melakukan gerakan untuk mencapai orientasi dan posisi yang dikehendaki [5]. Gambar 9 menunjukkan penempatan sumbu koordinat (frame) pada joint simulator arm robot berdasarkan kaidah tangan kanan.
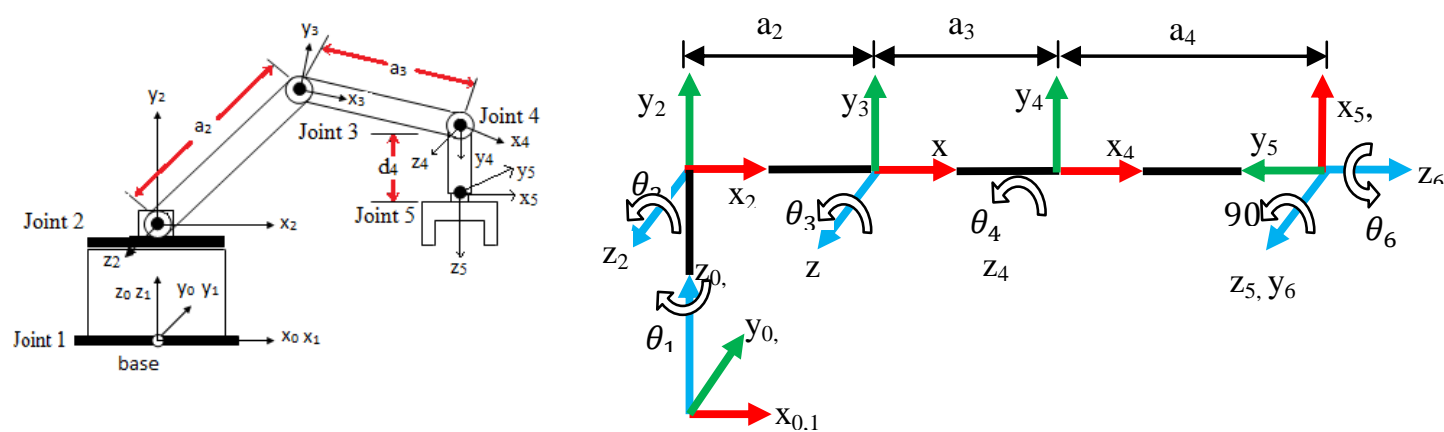

Gambar 9. Koordinat frames untuk arm robot 5 dof.

Simulator arm robot terdiri beberapa link dan joint. Joint digunakan untuk menghubungkan setiap link-link yang ada dimana setiap joint mewakili satu derajat kebebasan. Untuk mendeskripsikan hubungan translasional dan ratosional antara link-link yang berdekatan maka digunakan metode Denavit Hartenberg (DH) parameter sebagai sebuah metode matriks yang secara sistematis membangun sebuah sistem koordinat dari masing-masing link. Tabel 2 menunjukkan DH parameter simulator arm robot. Berdasarkan DH parameter tersebut, maka selanjutnya dapat ditentukan transformasi matriks tiap koordinat frame dari link i ke i+1 dengan menggunakan persamaan berikut ini:

$$
{ }_{i}^{i-1} T=\left[\begin{array}{cccc}
\cos \theta_{i} & -\sin \theta_{i} \cos \alpha_{i} & \sin \theta_{i} \sin \alpha_{i} & a_{i} \cos \theta_{i} \\
\sin \theta_{i} & \cos \theta_{i} \cos \alpha_{i} & -\cos \theta_{i} \sin \alpha_{i} & a_{i} \sin \theta_{i} \\
0 & \sin \alpha_{i} & \cos \alpha_{i} & d_{i} \\
0 & 0 & 0 & 1
\end{array}\right]
$$

Tabel 2. DH parameter untuk simulator arm

robot
\begin{tabular}{|c|c|c|c|c|}
\hline $\mathbf{i}$ & $\boldsymbol{\alpha}_{\boldsymbol{i}-\mathbf{1}}$ & $\boldsymbol{a}_{\boldsymbol{i}-\mathbf{1}}$ & $\mathbf{d}_{\mathbf{i}}$ & $\boldsymbol{\theta}_{\boldsymbol{i}}$ \\
\hline 1 & $0^{0}$ & 0 & 0 & $\theta_{1}$ \\
\hline 2 & $90^{0}$ & 0 & 0 & $\theta_{2}$ \\
\hline 3 & $0^{0}$ & $\mathrm{a}_{2}$ & 0 & $\theta_{3}$ \\
\hline 4 & $0^{0}$ & $\mathrm{a}_{3}$ & 0 & $\theta_{4}$ \\
\hline 5 & $0^{0}$ & $\mathrm{a}_{4}$ & 0 & $90^{0}$ \\
\hline 6 & $90^{0}$ & 0 & 0 & $\theta_{6}$ \\
\hline
\end{tabular}

Untuk menghitung forward kinematic, kita tentukan nilai $\mathrm{a}_{2}=119 \mathrm{~mm}, \mathrm{a}_{3}=165 \mathrm{~mm}$ dan $\mathrm{d}_{4}=47,5 \mathrm{~mm}$ berdasarkan panjang link simulator arm robot yang dirancang, dilanjutkan menentukan sampling nilai sudut $\boldsymbol{\theta}_{\boldsymbol{i}}$, misalnya $\boldsymbol{\theta}_{\mathbf{1}}=60^{\circ}, \boldsymbol{\theta}_{\mathbf{2}}=60^{\circ}, \boldsymbol{\theta}_{\mathbf{3}}=60^{\circ}, \boldsymbol{\theta}_{\mathbf{4}}=60^{\circ}, \boldsymbol{\theta}_{\mathbf{6}}=60^{\circ}$. Selanjutnya dengan menggunakan bantuan software MATLAB, maka diperoleh persamaan transformasi matriks yang menyatakan matrik orientasi dan vektor posisi dari base sampai dengan end effector sebagai berikut:

$$
\begin{aligned}
& { }^{0} T_{5}={ }^{0} T_{1} \cdot{ }^{1} T_{2} \cdot{ }^{2} T_{3} \cdot{ }^{3} T_{4} \cdot{ }^{4} T_{5} \cdot{ }^{5} T_{6} \\
& { }^{0} T_{6}=\left[\begin{array}{cccc} 
& \text { Matriks orientasi } & \text { Vektor posisi } \\
\hdashline 0,0000 & 0,8660 & 0,5 & 28,1997 \\
0,0000 & 0,5000 & -0,8660 & -48,8433 \\
\hdashline 1,0000 & 0 & -0,0000 & 197,8006 \\
\hdashline 0 & 0 & 0 & 1,0000
\end{array}\right]
\end{aligned}
$$


Untuk memverifikasi hasil perhitungan forward kinematic, maka akan digunakan software RoboAnalyzer seperti yang ditunjukkan pada Gambar 10. Dengan memasukkan dimensi link dan besar sudut yang sama nilainya ketika menggunakan MATLAB, maka akan diperoleh hasil sebagai berikut:

$$
{ }^{0} T_{6}=\left[\begin{array}{cccc}
1 E-05 & 0,8660 & 0,4999 & 28,1979 \\
-1,8 E-05 & 0,4999 & -0,8660 & -48,8419 \\
-1,0000 & 0 & 2,1 E-05 & 197,8018 \\
0 & 0 & 0 & 1,0000
\end{array}\right]
$$

Terbukti bahwa hasil perhitungan menunjukkan bahwa nilai matriks transformasi forward kinematics antara MATLAB dan RoboAnalyzer bernilai sama sehingga hal ini ini menunjukkan bahwa transformasi yang dilakuan tipa link telah benar.

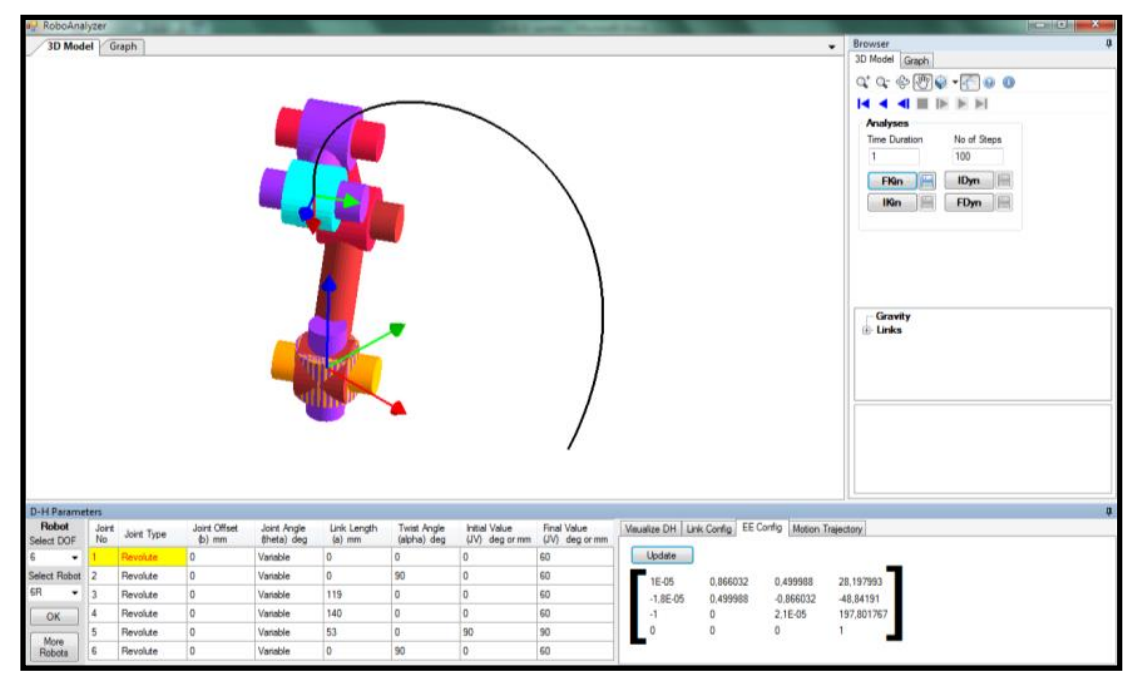

Gambar 10. Hasil transformasi forward kinemtic dengan RoboAnalyzer

\subsection{Desain software}

Untuk perangkat lunak, Firmata pada Arduino-LabVIEW interface digunakan yang terdiri dari 7 file yaitu LVIFA_Base, AFMotor.cpp, AFmotor.h, AccelStepper.cpp, AccelStepper.h, LabViewInterface.h, dan LabViewinterface. Gambar 11 (a) menunjukkan block diagram pada LabVIEW yang terhubung dengan Arduino untuk mengontrol servo motor melalaui front panel di LabVIEW yang ditunjukkan pada Gambar 11 (b).

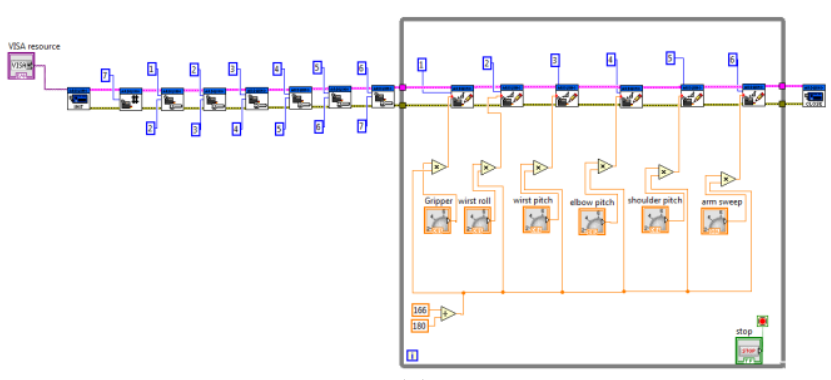

(a)

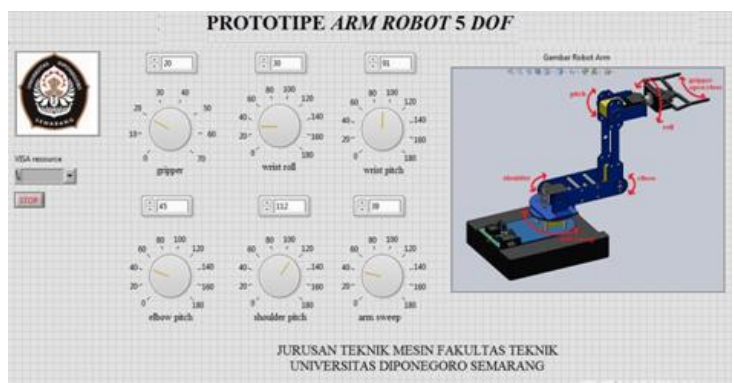

(b)

Gambar 11. Blok diagram arm robot pada LabVIEW (a) dan front panel arm robot 5 dof (b)

Pada saat pengujian, sudut yang dimasukkan pada LabVIEW tidaklah sama dengan posisi sudut sebenarnya pada servo motor. Dengan demikian diperlukan suatu koreksi menggunakan numerical divided dan numerical multiply. Numerical divided berfungsi untuk membagi input nilai yang dimasukkan, sedangkan numerical multiply berfungsi untuk mengkalikan input nilai yang dimasukkan. Pada hasil akhir terdapat kesalahan/ketidaksesuaian (error) sebesar $1,67 \%$ setelah input $180^{\circ}$ yang dihasilkan pada servo motor sebesar $183^{\circ}$. 


\section{KESIMPULAN}

Pembuatan simulator arm robot 5 dof ini untuk mempresentasikan robot manipulator sebagai salah satu dari robot industri yang berguna dalam proses pembelajaran robotika pada dunia pendidikan. Simulator arm robot dibuat dengan biaya terjangkau berbasiskan mikrokontroler Arduino Uno bersama LabVIEW untuk pembuatan front panel. Firmata digunakan sebagai interface antara Arduino dengan LabVIEW. Hasil verifikasi menunjukkan tingkat error antara sudut pada front panel dengan sudut aktual pada servo motor sebesar $1,67^{\circ}$. Nilai ini masih dalam range toleransi. Selanjutnya analisa forward kinematic telah mendeskripsikan orientasi dan posisi simulator arm robot 5 dof dari end effector terhadap base.

\section{REFERENSI}

[1] Craig, J., 1989, "Introduction to Robotics, Mechanics and Control, $2^{\text {nd }}$ Edition," Addison Wiley, Inc, New York.

[2] Scherz, P., Monk, S., 2008, "Practical Electronics for Inventors, Third Edition," McGraw Hill Professional, New York.

[3] LabVIEW, 1998, "Data Acquisition Basics Manual," National Instruments Corporation, Texas.

[4] Waren, J.D., Adams, J., and Molle, H., 2011, "Arduino Robotics," Apress, New York.

[5] Frankovsky, P., Hroncova, D., Delyova, I., Hudak, P., 2012, "Inverse and Forward Dynamics Analysis of Two Link Manipulator," Procedia Engineering, 48: 158-163. 